\title{
5. Basin Bookends, the Community Perspective $^{1}$
}

\author{
Leith Boully, Karlene Maywald
}

\section{Introduction}

There is a collective understanding across the Murray-Darling Basin (MDB) that water has been over-allocated, and, generally speaking, most people know in their hearts and minds that this must be addressed. Responding to calls from people across the nation (including in the MDB), the Australian Parliament passed the Water Act 2007 (Cwlth) with the support of the opposition and minor parties. With this level of consensus, it is reasonable to expect that implementation of the provisions of the Act would be well received. The Act has fundamentally redefined the water-policy priorities for the Murray-Darling Basin. It requires the preparation of a Basin Plan, which is the legal instrument with which the Australian Government has the capacity to return the system to a sustainable balance.

It is well understood by communities across the MDB that having a healthy environment is fundamental to economic prosperity and social harmony. So why has there been such an emotional outcry from individuals and communities to the release of the Guide to the proposed Basin Plan (MDBA 2010), which recommends the return of at least 3-4000 gigalitres of water to the environment? Could it be that the process and communication styles have so threatened people's core values and sense of identity and purpose that the only responses available are fight or flight?

This chapter seeks to put into perspective the communities' responses to the release of the Guide. It will demonstrate that process and communication are central to engaging individuals and communities in and achieving significant change. It will seek to make evident the need for a balanced environmental, economic and social response in shaping the final Basin Plan. Successful implementation of the Basin Plan is unquestionably one of the most important reforms facing our nation. The Australian commitment to a 'fair go for all'

\footnotetext{
1 The authors collectively have extensive experience working with regional communities in the MurrayDarling Basin. The opinions expressed in this chapter regarding the community are the views of the authors and have been drawn from these experiences.
} 
demands that we do it in a way that respects all of the individuals involved. We must get the balance right so the health of our rivers can underpin the future prosperity of our regions for generations to come.

\section{What Does Water Mean to People in the MDB?}

\section{Water is Life-We cannot survive without it}

There is nothing more important to Australians than water. The past 10 years of severe drought have severely impacted on the agricultural sector, but interestingly, the period has also highlighted the vulnerability of the nation's major-city water supplies. City and regional communities agree - they want to feel confident that governments are doing what is necessary to ensure greater certainty of water supply. There is also agreement that the environment needs its share.

\section{Our nation prospers from it}

Communities and industries have emerged from and grown on the back of development of the water resources of the Murray-Darling Basin. State Governments have actively promoted development based on the prosperity offered by irrigation, and communities have responded. According to the Guide, 'The Murray Darling Basin's agriculture produces \$15 billion worth of produce annually. It contains around $65 \%$ of Australia's irrigated land area and about $40 \%$ of Australia's farms' (MDBA 2010 pl3). The Basin is economically significant in terms of Australia's agricultural production.

\section{There currently are historical access and rights to it}

Irrigators own legally issued access entitlements to water. They have invested heavily in infrastructure to support their businesses based on their legal access to water. State and federal governments have invested heavily in:

1. river-regulation infrastructure - for example, dams, locks and weirs

2. irrigation-delivery infrastructure - for example, extensive channel systems, pumps, pipelines, and so on, to support the development of irrigation.

Each basin community has a different settlement story and each State has a different development story. Successive governments over-allocated wateraccess rights, and successive communities prospered and developed on the basis of the access rights legally issued. 


\section{Water Entitlement-Holders want to provide for their families from it}

Irrigators are people, running businesses, and providing for their families and/ or shareholders. Many families are attracted to irrigation towns where business opportunities and jobs provide the opportunity to bring lifestyle and livelihood together.

\section{Local Communities and the Nation Thrive from the Prosperity It Generates}

Communities have thrived and grown on the back of successful irrigation development. Communities have also struggled to cope when irrigation production has not performed well. Irrigators are risk takers. Irrigation businesses are subject to many variables: commodity prices, the Australian dollar, trade barriers, water availability, oversupply, under-supply, market failure, and the weather. Generations of irrigators have survived the cycles through extraordinary resilience and adaptively managing the changing economic circumstances. They are now overexposed as a result of previous government policy, which over-allocated water-access entitlements. Their future is uncertain.

\section{People want to camp, catch fish and yabbies, and love the environment it creates}

'The Murray Darling Basin consists of 23 major river valleys and covers one million $\mathrm{km}^{2}$ across four states and the ACT... Twenty of the 23 major river valleys of the Basin are in poor to very poor ecological condition' (MDBA 2010 p13). A do-nothing scenario will lead to further degradation and possibly irreversible decline in the health of the system. This is not the future that basin communities want for future generations.

\section{So why is getting the balance right so hard?}

No matter where you stand in the Basin, communities look upstream with envy and downstream with disdain. All people see the problem through the lens of their own circumstances and limited knowledge: 'Of course it should be fixed, but why is it my fault? Why should I wear the cost of fixing it? Governments stuffed it up, so Governments should fix it.' This is a normal human response to a threat to personal security. 


\section{Process}

The thing that we have to understand is that values and ethics are not formed overnight. They are deep seated. So persuasion and manipulation towards solutions that do not include community values and ethics are a waste of time and of money. (Nancarrow 2006)

Criticism of process and at least a perceived lack of communication have been the dominant issues raised by commentators from across the MDB regarding the Guide to the draft Basin Plan. Linked closely to this has been a call for amendments to the Water Act to allow for the 'proper' consideration of social and economic issues and robust community-engagement processes. The definition of 'proper', however, changes depending on the perspective of the individual.

'The truth is that irrespective of whether you live in Adelaide or Griffith, Dirranbandi or Waikerie, water is not only technical it is social-how it is used or abused is about people and their values, needs and aspirations' (Boully 2010, p 1).

It is not possible to 'fix the problem' without tackling the needs of the people affected by the proposed changes.

A complicating factor is that the values, needs and aspirations of people will differ greatly from community to community, region to region and State to State.

It does not help that the Murray-Darling Basin is littered with historical prejudices and spin. Every community, industry sector, local government and State government is guilty of pointing the finger and playing the blame game.

South Australians blame greedy upstream States and rice and cotton growers, while upstream they think South Australians are just a bunch of whingers and cannot understand why the barrages are not opened to flood the Lower Lakes with sea water.

Right across the Basin there are cries of 'It's not my fault'; 'It has to be fixed but why should I bear the brunt of the cost'; 'The numbers can't be right'; 'The environment is important, but so is my family/community'; 'I've done my bitlook how efficient I am.'

Decades of entrenched, ill-informed prejudices fuelled by local political point scoring have tended to polarise the debate.

Add to this a deep cynicism of government and a media that will always prefer controversial opinion to boring facts and it is easy to see why decision makers have shied away from making the tough decisions. 
We can draw on recent experience to look for alternative processes. The development of the concept of a 'healthy working river' as a means to reconcile multiple values and objectives in the Living Murray Initiative (Murray-Darling Basin Commission: <http://thelivingmurray2.mdbc.gov.au/>) was a critical contribution to the success of what was the first step taken by the MurrayDarling Basin Ministerial Council to improve the health of the MDB.

A healthy, working river is defined as a river that is managed to provide a sustainable compromise, agreed to by the community, between the condition of the river and the level of human use (Cooperative Research Centre for Freshwater Ecology 2003). Implicit in this definition is the recognition that a complex sociobiophysical system exists and that rigorous processes must be provided through which the community and governments can, in an informed manner, negotiate a range of trade-offs or optimise objectives.

This language engaged the hearts and minds of basin communities so that the process and subsequent decisions were warmly embraced.

The National Water Initiative (NWI) (Commonwealth of Australia 2004), which has widespread stakeholder support, recognised that settling the tradeoffs between competing outcomes for water systems will involve judgments informed by the best-available science, socioeconomic analysis and community input. Open and inclusive discussion of the range of values held by different interests must be incorporated into the process. The values held collectively in relation to water, rivers and groundwater systems can, if properly explored, lead to the development of an ethical framework through which to negotiate objectives and management arrangements (Boully 2007).

The Guide to the proposed Basin Plan has, for the most part, been designed by scientists, engineers and other technical experts, with little input from planners and social scientists. The NWI has established the theoretical opportunity for communities and governments to develop sophisticated, values-based, ethical adaptive-management arrangements, while it appears that the Water Act has restricted this philosophical approach.

The process adopted by the Murray-Darling Basin Authority (MDBA) to date has followed the approach that governments have traditionally employed in relation to water-resource planning - that is, an adversarial and expert decisionmaking approach to water allocation, management and planning processes. This has been described by Vanderbyl and Boully (2004), who suggest that such approaches tend to

- rely mainly on the input of scientific experts, scientific organisations, lobbyists or other people who might be strongly aligned with particular 'sides' or a specific point of view 
- place emphasis on the importance of research, technical reports or other information generated for a specific purpose and without reference to, or integration with, other work that might be relevant

- involve decisions to strategically either withhold or release information (rather than to openly pool it)

- keep 'grassroots' stakeholders at arm's length from committees, expert panels or other administrative or scientific bodies involved in the decisioninforming stages of the processes

- take no account of the professional and personal damage done to individuals on all 'sides' through the highly emotive and destructive approaches people feel forced to adopt in order to have their view heard.

Every decision has impacts that are felt in both positive and negative ways across river reaches and communities. Every refinement has a new set of impacts. What is fair to people with one set of values will be seen as unfair to others. Only rigorous processes that take account of these issues can reduce the potential for conflict, or manage it well, by ensuring that the decisions are defensible on a broad range of grounds (Vanderbyl and Boully 2004).

Only a sophisticated and well-resourced adaptive-management philosophy, framework and practice will meet the multiple and changing values and objectives of the mature water economy. Vanderbyl and Boully (2004) conclude that the primary objective of reform must be the development of rigorous, adaptive, inclusive, informed and fair processes for managing complex waterresource systems.

The voices of individuals and communities across the MDB suggest that these processes are absent.

\section{Communication}

It is said that 'communication is the response that you get'.

Senior officials in the MDBA point out that they have acted in accordance with the Water Act, which was passed unanimously by both houses of the Commonwealth Parliament. They are communicating the 'facts' about the state of the rivers of the $\mathrm{MDB}$ and the rational solution to the challenge of overallocation. Why, then, is this not getting traction and support?

Olson (2009), in his book Don't Be Such A Scientist: Talking substance in an age of style, tells us that there are 'layers' of communication, rather like a pyramid. At the top of the pyramid is the 'mind', which is arguably where most scientists and policy makers spend most of their time. They communicate learnedly with each other in a careful, heavily footnoted style. The next layer down is the 'heart': the locus of love. The third layer is the 'gut': the locus of fear. 
The MDBA's interpretation of the Water Act has caused it to focus on the science first and the community second. The Authority has tried to communicate to people who are not 'just like them' through engaging with the mind in a logical and rational manner. They have failed to engage the hearts by neglecting the social and economic matters that are as fundamental to an individual's survival as the water itself. People have received the communication as a blow to the gut. They are now fearful for their basic survival and their very identities are threatened. There is a very real risk that the extreme polarisation of the debate will result in decisions being made that will be detrimental to the Basin environment, its communities and individuals.

\section{Creating the Environment for Change}

Bringing about sustainable change requires that people believe there is a need for change, are committed to it, know how to go about it and have sufficient resources to do so.

In order to create the environment for change given the current circumstances, a rethink of the processes being employed is required. This rethink should take into account Ingram and Schneider's (1998) proposition that water is a fundamental social resource, and collective decision making about its distribution and protection is fundamental to building a sense of community. This sense of community is important for building resilience and to assist difficult decision making that affects community, rather than individual, interests.

In relation to rivers and groundwater systems, the behaviour of communities is strongly influenced by how they value water. Different beliefs and values will lead people to define water in terms of how it can provide: economic opportunity; recreational opportunity; cultural and spiritual needs; basic drinking needs; places of great beauty; abundance of wildlife; and other ecosystem services. Whilst all communities have deeply entrenched beliefs and value systems, they are not necessarily the same across the Basin. The impacts of the Basin Plan will be felt differently in each community depending on their socioeconomic status and their capacity to afford to manage the necessary changes. Programs to deal with the impacts will need to be flexible enough to respond to the specific needs of each community.

Adopting a bottom-up approach to enable communities to determine what the future might look like for them in an environment with less water would deliver better results than a top-heavy, 'one-size-fits-all' approach. Transition time frames will also be important as large volumes of water are transferred from economic use to the environment. Providing support for communities to play a part in determining what programs will best suit their local needs will empower them to think about how they can influence their own future. Communities 
cannot yet see what the future looks like in an environment with less water. They need help to participate in designing a future that will sustain them and their children and grandchildren.

There is a need for a new process at the regional scale that can take account not only of economic values and interests in water, but also - more explicitly - the social and cultural values that underpin them. These processes will enable policy makers and planners to explore the full range of strategies that can be used to respond to the diversity of values and motivations within the community and the attitudes and behaviours that result (Boully 2007).

Key features that should be evident in the process include

- formal and permanent engagement arrangements focused on improving water-resource management and meeting community aspirations

- a focus on joint discovery and mutual-gains decision making in realistic time frames

- consideration of a broad range of economic, social and environmental interests

- processes to identify and manage conflict

- commitment to building the capacity of those in the community who have trouble participating due to lack of knowledge or for social or economic reasons

- innovation in the provision of environmental flow

- certainty that rights are secure and that the market will be used to adjust levels of consumptive use

- establishment of multiple objectives that reflect multiple values that are measurable.

With the appropriate process in place, the grassroots players will be able to be proactive in designing a future rather than devoting that energy to trying to destroy a top-down process.

\section{Who Are the Players Today?}

\section{Retirees}

The average age of our farmers is fifty-eight and many sons and daughters are not likely to take over the family farm. This means that for some irrigators the answer will be to exit irrigation and retire from the land. Selling water at market rates might be attractive, however, the capital will most likely go to retire debt and perhaps fund resettlement. It will not necessarily stay in the community. 
In addition, the land will be rendered unproductive in many districts and irrigation-delivery infrastructure might be stranded, resulting in increasing costs to the stayers.

\section{Stayers}

For those who stay, the cost will be significant. Despite the short-term policy of allowing irrigation-infrastructure operators to charge modest exit fees to cover the cost of asset rationalisation, it will not mitigate the very significant issue of stranded assets. Irrigation fixed costs will be a significant impediment to the profitability of the stayers. In addition, the stayers will be subjected to the increasingly conservative lending criteria of the banking sector due to their perceptions of the risks inherent in and consequential to the reform process.

\section{Others}

The non-irrigator population of the small and medium-sized towns in the MDB who are reliant mostly on agriculture for their sustainability will face significant challenges. As economic output declines, jobs are lost and services downsized or removed. While this is the way it has always been, there has never been a policy shock of the scale of that proposed by the Guide to the proposed Basin Plan and it is difficult to imagine any complementary or replacement industry emerging to mitigate the impact. That being the case, it is only fair that these communities are provided with the processes and resources to plan the adjustment.

\section{Finding the Way Forward}

The release of The Guide to the proposed Basin Plan is the first glimpse the community has had of the work undertaken by the independent MDBA in accordance with the Water Act. Public meetings have been held throughout the Basin as the first step in the consultation process and irrigation communities have turned out in droves to express their opposition to the quantum of water proposed for return to the environment. It is not surprising that the initial reaction from irrigation communities is one of anger and opposition. Communities are frightened by what the future will hold for them and they lack confidence in the decision-making process.

What has become evident very early is that a process to deal concurrently with the social and economic issues is missing. The Minister for Regional Development has subsequently announced that a Parliamentary Inquiry will be held into the social and economic issues of the proposed Basin Plan. The original vision for 
minimising the impact of the necessary reform included significant investment in infrastructure-upgrade programs to save water and water-purchasing programs. Water-purchase programs compensate an entitlement-holder for giving up water, while investment in infrastructure provides support for those staying in the irrigation industry, saving water through efficiency gains and creating employment. While there has been criticism of the way in which both approaches have been implemented, there is no doubt that the withdrawal of investment from either program would create yet more conflict.

For some time community advocates have been desperately trying to impress on the Australian Government that while individual irrigators might be treated fairly in a financial sense, their communities have no safety net to rely on. What is missing is a program that will support the development of a new vision for the future and deal with the broader-reaching social and economic impacts.

Knowing the real impact of the proposed Plan on regional communities is important, but it is equally important to determine what needs to be done about it. Those best placed to do this are the communities themselves. Acknowledging the fact that water reform is a social process and, based on successful experiences in South Australia and Queensland, we would argue that in addition to the existing process there are three critical steps required to re-engage communities in designing their future in an environment where less water is available for consumptive use.

\section{Recommit to sustainability}

Recommit to the concept of achieving healthy, working rivers in the MDB. The MDBA should support and resource State governments to engage their communities in water-resource planning processes including designing stepped approaches to achieving the environmental outcomes articulated in the Guide to the proposed Basin Plan and taking into account the social and economic consequences of doing so. Application of local knowledge will reveal much more sophisticated and efficient means to provide water for key ecological assets and functions than can be achieved from an office in Canberra.

The evidence that this can be done is provided by Vanderbyl and Boully (2004, p 1), who summarise a very successful and timely process undertaken in 2002 in the Lower Balonne, Queensland, as follows:

Water sharing between users and between users and the environment has been a focus for the Lower Balonne community for a long time. Conflict between users within the community and between community and government has been significant for over a decade. Both government 
and the community have been able to rise to the challenge, put the past behind them and develop an approach to sharing water resources between competing values.

Through the use of the best available hydrologic data and ecological science community and government have together acknowledged the risks to specific ecological assets, and to the economic viability of the region if the 'business as usual' scenario is adhered to. With the ultimate goal being the establishment of 'social harmony' the process of learning, debate and negotiation has successfully dealt with equity between most users and between users and the environment.

Government has taken the unprecedented step of providing unrestricted access to all information and adequately resourcing the process of supporting a community reference group. This group has been able to interact directly with an independent Scientific Review Panel and in partnership with government subsequently develop through a process of 'joint discovery', innovative solutions to the challenges involved in managing a large, ephemeral floodplain river system with multiple values.

\section{Support for regional communities}

The Australian and State governments should jointly fund regional communities to develop adjustment prospectuses and provide investment capital through a future fund.

An example of a regional development program designed to assist communities to adjust is the SA Government-funded 'Riverland Futures' program.

The Riverland is a SA irrigation-based community that has been hard hit by the drought.

The Riverland Futures Task Force was established to drive the program. The Task Force was made up of local government mayors and CEOs and leaders from the local health, education and industry sectors, primary industries and regional development officers.

The SA Government provided funding to prepare a Riverland Prospectus to explore development opportunities and guide investment in the region. It sets out the region's goals and aspirations, its strengths and weaknesses and the opportunities to diversify the economic base.

The SA Government has also committed $\$ 20$ million as seed funding to support projects that meet investment criteria. 


\section{Invest}

The Australian Government should significantly increase investment in irrigation research and development with the goal of bringing about transformational change to both practices and production. Australian agriculture has a proud history of generating growth in productivity and innovation in environmental practice. Sustained high levels of investment in this professional and innovative sector would be a mark of respect for those who produce some of the best food and fibre in the world.

We would not suggest that these are the only ways to retrieve what has become a sad and divisive argument about the most precious of our resources, people and water, but our practical and pragmatic community experience leaves us in no doubt that significant initiatives in these three areas would provide hope to those who have lost it and produce sustainable outcomes for the environment and communities. Even though there will be many who would say that this will take too long, we are in no doubt that continuing the current adversarial approach will take even longer and have fewer beneficial outcomes.

\section{References}

Boully, L. 2007, 'Water resource management: multiple values demand multiple objectives', Farm Policy Journal, vol. 4, no. 13 (August Quarter).

Boully, L. 2010, The water dance, Presentation to the Australian Academy of Science, Canberra.

Commonwealth of Australia 2004, Intergovernmental Agreement on a National Water Initiative, Commonwealth of Australia, Canberra.

Cooperative Research Centre for Freshwater Ecology 2003, Ecological assessment of environmental flow reference points for the River Murray system, Interim report prepared by the Scientific Reference Panel for the Living Murray Initiative, Murray-Darling Basin Commission, Canberra.

Ingram, H. and Schneider, A. 1998. 'Science, democracy and water policy', Water Resources Update, vol. 113, no. 21-28. < http://www.ucowr.org/ updates/113/index.html>

Murray-Darling Basin Authority (MDBA) 2010, Guide to the proposed Basin Plan, Murray-Darling Basin Authority, Canberra. 
Nancarrow, B. 2006, Social sciences-ethics, attitudes and trust in water management, Proceedings of the Australian Academy of Sciences' High Flyers Think Tank Conference on Innovative Technical Solutions for Water Management in Australia, Adelaide, 30 October, <http://www.science.org. au/events/thinktank2006/nancarrow.htm>

Olson, R. 2009, Don't Be Such a Scientist: Talking substance in an age of style, Island Press, Washington, DC.

Vanderbyl, T. and Boully, L. 2004, Rising to the challenge-developing a community-based solution to water sharing in the Lower Balonne in Queensland, Paper presented to the Irrigation Australia Conference, Adelaide, 11-13 May. 